\title{
Coagulation disorders in SARS-CoV-2 infection
}

\author{
Romeo Gabriel Mihailaa, Marius Dragos Mihaila ${ }^{b}$
}

\begin{abstract}
A better understanding of the pathogenetic mechanisms triggered by SARS-CoV-2 infection may contribute to a more effective management of patients with COVID-19. Coagulation dysfunction is a key pathogenetic element of this disease as well as a challenge for practitioners. Marked inflammatory process found in severe forms of COVID-19, the complement activation, the cytokine storm, and disruption of the renin-angiotensin-aldosterone system are involved in the onset of thrombotic microangiopathy and large vessel coagulopathy. Virus-induced procoagulant activity occurs at the systemic level. Intravascular microthrombi disrupt vascularization in various tissues and organs, contributing to the occurrence of multiorgan failure and explain the higher morbidity and all-cause mortality of patients. It is estimated that almost $20 \%$ of patients with COVID-19 have significant coagulation disorders, and about a quarter of those hospitalized in intensive care units are prone to develop thrombosis events under prophylactic anticoagulant treatment. Some of patients who have been immunized after healing from the SARS-CoV-2 infection have a hypercoagulable state and are prone to develop thrombosis. Hypercoagulability is supported by thrombelastographic analysis: patients have an acceleration of the propagation phase of blood clot formation and higher clot strength. Markers of coagulation dysfunction in SARS-CoV2 are: decreased platelet count, increased INR, presence of fibrin degradation products, and especially higher plasma levels of D-dimers, which predict unfavorable outcome in these patients. Age, pre-existing diseases and associated risk factors, together with careful monitoring of clinical evolution and laboratory parameters allow the choice of the best personalized prophylactic or curative anticoagulant treatment.
\end{abstract}

Key words: coagulation disorders, COVID-19, heparin, SARS-CoV-2, thrombosis

Received: August 2, 2020; Revised: August 26, 2020; Accepted: September 2, 2020; Available online: September 9, 2020

https://doi.org/10.5507/bp.2020.037

(c) 2020 The Authors; https://creativecommons.org/licenses/by/4.0/

${ }^{a}$ Faculty of Medicine, "Lucian Blaga" University of Sibiu, and Department of Hematology, CVASIC Laboratory, Emergency County Clinical Hospital Sibiu, Romania

"Faculty of Medicine, "Iuliu Hațieganu" University of Medicine and Pharmacy, Cluj-Napoca, Romania

Corresponding author: Romeo Gabriel Mihaila, e-mail: romeomihaila@yahoo.com

\section{INTRODUCTION}

The severe acute respiratory syndrome coronavirus 2 (SARS-CoV-2) pandemic began in China and spread around the world in a matter of months ${ }^{1}$.

Collaboration between teams of researchers around the world has been and is essential for conducting clinical trials in coronavirus disease 2019 (COVID-19) infected patients in order to understand the pathophysiological features of this new viral challenge ${ }^{2}$.

Coronavirus disease 2019 (COVID-19) is pathogenetically associated with inflammation, cytokine storm, and frequent lung injury ${ }^{3}$ but multiple tissues and viscera can be affected, a situation which acquires a systemic character. The decrease in peripheral blood lymphocyte count was sometimes observed early in severe COVID-19 cases and reported before disease progression or death in all 10 patients who were autopsied in a study in Wuhan. They showed lymphoid atrophy of the splenic follicles and a decrease in the number of splenic $B$ and $T$ lymphocytes $^{4}$. In addition, endothelial damage may explain the systemic impairment present in some patients ${ }^{5}$. The virus binds to angiotensin-converting enzyme 2 . Depletion of this enzyme by the virus results in an increase in the amount of angiotensin II, which has proinflammatory and vasoactive effects and promotes tissue damage. It is accepted that the patients infected with SARS-CoV-2 have a thrombotic risk. The coagulopathy present in patients infected with SARS-CoV-2 is similar to the one induced by sepsis ${ }^{6}$. Thrombotic events (venous and arterial thromboembolism) ( ref. $^{7}$ ) occur more often in patients with more severe disease who also have other risk factors, such as male gender, advanced age, obesity, cancer, different comorbidities, and treatment in intensive care units ${ }^{3}$.

\section{PATHOGENETIC MECHANISMS TRIGGERED BY SARS-COV-2 INFECTION}

The sequence of pathogenetic events in patients with severe forms of COVID-19 is: alveolar lesions caused by the virus, followed by a reactive inflammatory process, which promotes the occurrence of thrombosis in the pulmonary microcirculation. Inflammatory and thrombotic endothelial lesions have been observed in the brain and other vital viscera, which can progress to multiorgan failure and even death ${ }^{8}$. 
The role of the immune mechanism and the hypothesis of autoimmune involvement

Lymphopenia and decreased helper and suppressor lymphocyte disturbances upset the balance between innate and acquired immunity and increase neutrophilic and macrophage stimulation. Persistent activation of the immune system can lead to hemophagocytosis-like syndrome, with a significant increase in cytokine release, which can cause multiple organ failure and even death ${ }^{9}$. On the other hand, the cytokine storm, along with ischemia and hypoxemia, are involved in the appearance of immune lesions ${ }^{10}$. Fixation of the virus to the angiotensinconverting enzyme-2 (ref. ${ }^{11,12}$ ), followed by cell penetration and infection, could be involved in the development of the autoimmune response, with the production of allo- or autoantibodies against the enzyme, which could explain some late, severe complications. This is just a hypothesis, which requires further study for confirmation ${ }^{11}$.

\section{The role of neutrophil extracellular traps}

Neutrophils may release neutrophil extracellular traps, but when they are dysregulated they have a proinflammatory effect and a prothrombotic role at microvascular level, including in severe forms of COVID-19 pneumonia that progress to acute respiratory distress syndrome. Some markers of neutrophil extracellular traps are elevated in COVID-19 (especially in the patients subjected to mechanical ventilation procedures) and correlated with peripheral neutrophil count. They are involved in the cytokine release and progression to respiratory failure ${ }^{13}$. In addition to thrombosis in the microcirculation, thrombotic events (affecting large vessels) are more common in patients with severe COVID-19 pneumonia.

\section{Deregulation of coagulation and fibrinolysis}

The risk of arterial and venous thrombosis in patients with severe forms of COVID-19 or with systemic manifestations is explained by the presence of expressed inflammatory syndrome, hypercoagulability, endothelial dysfunction, platelet activation, and blood stasis ${ }^{14}$. Deregulation of coagulation and fibrinolysis in COVID-19 patients results in fibrin deposits in the alveoli and lung parenchyma. Tissue factor (released from lesions of alveolar endothelial cells and on the surface of leukocytes) is involved in the formation of these deposits. Increased amounts of plasminogen activator inhibitor factor 1 are released from vascular endothelial cells and lung epithelium and contribute to hyperfibrinolysis ${ }^{15}$.

\section{COAGULATION DYSFUNCTION REFLECTED IN CLINICAL AND LABORATORY CHARACTERISTICS OF SARS-COV-2 INFECTION}

An early and accurate diagnosis of COVID-19 is essential to ensure appropriate treatment, to limit the worsening of viral disease, and, at the same time, contribute to the control and elimination of the SARS-Cov-2 epidemic $^{16}$. This viral infection may be asymptomatic or cause the disease. Fever and upper and lower respiratory tract symptoms and signs (especially dry cough, and shortness of breath, but also fatigue, headache, myalgia, or diarrhea) are the main clinical manifestations of this disease ${ }^{1,5,12}$. Acute respiratory distress syndrome can be added to these $\mathrm{e}^{7,12}$. Chinese authors report that about $20 \%$ of patients infected with SARS-CoV-2 have severe forms of the disease ${ }^{17}$.

\section{Arterial and venous thrombosis and hemorrhages}

With the increase in the number of treated patients, the number of communications regarding the systemic implications of COVID-19 infection, including the cardiovascular and neurological ones, has increased. Among the latter are: both venous thrombosis or cerebral infarctions, but also intracerebral hemorrhages ${ }^{1}$. Arterial thromboses are also possible (e.g. of the superior mesenteric artery) (ref. ${ }^{18}$ ), as well as the combination of arterial and venous thrombosis (e.g. of the superior mesenteric vessels) $\left(\right.$ ref. $\left.^{19}\right)$. Even unenhanced computed tomography scan can signal indirect signs of thrombosis, which the radiologist must pay attention to ${ }^{19}$. But the first clinical manifestation of SARS-CoV-2 infection may also be a thrombotic event, such as: venous thromboembolism, pulmonary embolism, carotid artery thrombosis, stroke, cerebral venous sinus thrombosis, or coronary thrombosis ${ }^{20}$. It is known that venous thromboses are more common than arterial thromboses in antiphospholipid syndrome. The latter are most often manifested by ischemia or infarction ${ }^{21}$. The fact that venous thromboses are also more common than arterial thromboses in coagulation dysfunction present in patients infected with SARS-CoV-2 could be partially explained by the incidence of lupus anticoagulants in these patients.

\section{Thrombotic microangiopathy}

Thrombotic microangiopathy of the heart is responsible for the occurrence of myocarditis, various forms of cardiac arrhythmias, acute coronary syndrome, heart failure, and even sudden death, complications that occur more frequently in patients with pre-existing cardiovascular disease ${ }^{9}$.

\section{Hypothesis: thrombosis in the pulmonary circulation induced by SARS-CoV-2 could aggravate the disease}

One hypothesis is that thrombosis in the pulmonary circulation induced by SARS-CoV-2 may cause sudden aggravation of the disease and even death. A severe disease is suggested by a level of D-dimers above $500 \mathrm{ng} / \mathrm{mL}$, and a possible death - by a level above $1000 \mathrm{ng} / \mathrm{mL}$. Frequent damage in the lower lobe and peripheral lung regions is an argument for the potential thrombotic role of this virus ${ }^{22}$.

\section{The controversial role of antiphospholipid syndrome}

Harzallah et al published the results of a study that included 56 patients infected with or suspected of having SARS-CoV-2. Nearly half of them had lupus anticoagulants, while five patients were positive for either anticardiolipin or anti- $\beta 2$-glycoprotein I antibodies ${ }^{23}$. But there are authors who do not believe that the incidence of an- 
tiphospholipid antibody is so high in COVID-19 patients. Some of the patients investigated by Harzallah et al with such antibodies met the diagnostic criteria for disseminated intravascular coagulation ${ }^{24}$.

\section{Laboratory markers with a prognostic role}

Heart disease caused by SARS-CoV-2 is manifested by elevated values of natriuretic peptides and highly sensitive troponin, which have prognostic value, especially when they increase continuously, in parallel with IL-6 (ref. ${ }^{9}$ ).

\section{Thrombosis discovered at autopsy}

An autopsy performed in 12 consecutive patients with confirmed COVID-19 detected the presence of deep venous thrombosis in $58 \%$, although it was not suspected before death ${ }^{25}$.

\section{DIAGNOSTIC PARTICULARITIES}

SARS-CoV-2 is a single-stranded RNA virus that produces mainly respiratory signs and symptoms, but also hematological damage and significant coagulation disorders, involved in the pathogenesis of the disease ${ }^{26}$. Angiotensin converting enzyme 2 is mostly expressed in the lung, small bowel, and blood vessels, so that the viscera can be damaged by SARS-CoV-2 infection because this enzyme is a viral taget ${ }^{27}$. Diffuse alveolar lesions caused by the virus, along with multiple organ dysfunctions and predisposition to microthrombosis in various tissues and organs and even the formation of macrothrombi are features of SARSCoV-2 infection that explain the worse prognosis of severe forms and the challenges of their complex management ${ }^{10}$.

\section{Pulmonary radiological features with diagnostic role}

Radiological changes are an important criteria for suspecting COVID-19 and a reason to perform virological determinations even in asymptomatic subjects. They are present even after death. Reticular infiltration along with bilateral dense consolidation were observed in the lungs of patients with COVID-19 in postmortem computed tomography examination ${ }^{25}$.

\footnotetext{
Abdominal changes

The computer tomography-scan can detect pneumatosis or portal venous gas at the bowel level in $20 \%$ of patients with severe COVID-19 in intensive care units. Another imaging finding in these patients is the presence of cholestasis. Surgeons may report a yellow discoloration of the bowel and the presence of bowel infarction. Pathological examination of the intestine may find ischemic enteritis with areas of necrosis and fibrin thrombi in the lumen of arterioles ${ }^{27}$.

\section{Peripheral ultrasonographic examination}

Examining the lower extremity using ultrasound is useful for the detection of deep vein thrombosis, but it must be made after the application of protocols for machine disinfection, to prevent the spread of infection ${ }^{28}$.
}

\section{Hematological, inflammatory and coagulation parameters with a prognostic role}

Lymphopenia is characteristic of SARS-CoV-2 infection and has prognostic value ${ }^{29}$. Decreased lymphocyte population and the presence of hemorrhagic necrosis in the spleen and lymph nodes could be an explanation for lymphopenia ${ }^{10}$. Peak platelet / lymphocyte and neutrophil / lymphocyte ratios are other parameters with prognostic value in severe forms of COVID-19. Indices of unfavorable prognosis are also accentuation of the lymphopenia and the progressive increase in the inflammatory markers during the evolution of the disease. Elevated serum ferritin and procalcitonin also draw attention to a negative prognosis. Progressive increase in plasma levels of D-dimer is an indicator of COVID-19 worsening ${ }^{29}$. The tendency for microvascular thrombosis in the lungs and other viscera is frequent in COVID-19 and less mentioned in the severe acute respiratory syndrome (SARS) $\left(\right.$ ref. $\left.^{10}\right)$.

\section{Procedure for monitoring COVID-19 suspected / positive patients}

SARS-CoV-2 infection can complicate the progression of many diseases. Therefore, the prompt and appropriate recognition, isolation and treatment of infected patients is essential.

Any patient with the respiratory symptoms mentioned above, but also those with diarrhea or abdominal pain, with any thrombotic manifestation, recent rashes, loss of taste or smell should be tested for the presence of infection by RT-PCR nucleic acid test. Also in the absence of these manifestations, any subject who came into close contact with a patient infected with SARS-CoV-2 (without a mask and protective gloves) or who stayed in the same room with him for more than 15 minutes must be tested. In addition, any patient should be tested before hospitalization. Cancer patients undergoing chemo- or radiation therapy should be tested twice a month, as well as patients undergoing hemodialysis procedures for chronic kidney failure.

If the RT-PCR nucleic acid test is negative but the suspicion of infection with this virus persists, a chest computed tomography is indicated. The presence of ground-glass opacity and patchy consolidation are commonly found in COVID-19 patients ${ }^{30}$. Slightly increased, but far less than $0.5 \mathrm{ng} / \mathrm{mL}$, procalcitonin levels are found in SARS-CoV-2 infected patients, as well as decreased or normal urea and creatinine levels, arguments that differentiated these patients from controls (who were suspected of had this infection) in a study in Wuhan ${ }^{31}$. Arguments for a SARS-CoV-2 infection are also the altered levels of D-dimers, activated partial thromboplastin time (aPTT), prothrombin time (PT), fibrinogen, and platelet count discussed above, in a patient with inflammatory syndrome.

The RT-PCR nucleic acid test should be repeated when there are clinical or biological arguments that the patient may be infected. During hospitalization, repeated clinical, biological and imaging monitoring of patients is indicated (last even at 3 days interval if necessary and possible). Patients with COVID-19 should not be dis- 
charged prior to 2 successive negative tests with an interval of $24 \mathrm{~h}$. Subsequently, their clinical monitoring is recommended for at least two weeks, because a positive RT-PCR nucleic acid test does not always reflect the former patient's infectivity. If symptoms recur, the RT-PCR nucleic acid test should be repeated. Its positivity, in this situation, is an argument for the recurrence of the disease. Imaging control is also useful, especially if the RT-PCR nucleic acid test is negative.

\section{COAGULATION DYSFUNCTION IN SARS-COV-2}

Observations on the clinical course of severe forms of COVID-19 found a marked inflammatory process and a disruption of the renin-angiotensin-aldosterone system, associated with micro- and macroangiopathy (a combination of thrombotic microangiopathy with large vessel coagulopathy) (ref. ${ }^{32}$ ). Coagulation activation is triggered by the cytokine storm produced by SARS-CoV-2 (ref. ${ }^{33}$ ). Indeed, it appears that the inflammatory response activates coagulation in SARS-CoV-2 infection and not the properties of the virus ${ }^{34}$. Activation and damage of endothelial cells is the result of tropism of the virus for angiotensin-converting enzyme 2 receptors. This explains the disruption of the natural antithrombotic state. Vascular endothelial dysfunction promotes microcirculatory clot formation. Cerebrovascular and myocardial complications, and micro- and macrocirculatory thromboembolism may also occur in young patients as a result of virus-induced endotheliopathy ${ }^{34}$.

\section{Epidemiological data on thrombotic events}

Hospitalized SARS-CoV-2 infected patients are frequently elderly and immobilized so that they are prone to thrombosis. But they also have signs of coagulopathy. In addition, the estimated incidence of thrombotic events is not negligible: about a quarter of those infected with the virus and hospitalized in intensive care units are prone to develop thrombosis even under prophylactic anticoagulant treatment ${ }^{35}$. The incidence of venous thromboembolism in patients hospitalized in intensive care units for COVID-19 appears to be higher than in those with other conditions predisposing to thrombotic complications $^{36}$. The cumulative incidence of venous thromboembolism was $16 \%$ after one week and increased to $42 \%$ after 3 weeks in a group of 198 hospitalized patients with COVID-19 analyzed in a single-center study, despite the prophylactic anticoagulant therapy. Symptomatic cases were rarer ( $10 \%$ and $25 \%$, respectively). This complication was more common in hospitalized patients in the intensive care unit (26\% and 59\%, respectively) (ref. ${ }^{37}$ ).

\section{Is there a thrombotic or hemorrhagic risk?}

Patients with severe COVID-19 pneumonia have both thrombotic and hemorrhagic risk ${ }^{38}$. But the thrombotic risk predominates in these patients; hemorrhages are rare $^{39}$. The association of bleeding and recurrent extensive arterial thrombosis was also observed in a patient with COVID-19 and acute promyelocytic leukemia, which progressed dramatically ${ }^{40}$.

The disseminated presence of intravascular microthrombi disrupts vascularization in various tissues and organs, contributing to the occurrence of organ failure, similar to the situation present in severe sepsis ${ }^{33}$. Coagulation dysfunction in these patients is linked to the most severe course of the disease, with multiple organ failure and even death ${ }^{33}$. Therefore, the increased thrombotic risk of patients infected with COVID-19 contributes to their higher morbidity and mortality ${ }^{41}$.

\section{Plasma fibringen and D-dimer levels}

An analysis of 67 patients infected with SARS-CoV-2 and who had acute respiratory disease had significantly higher plasma fibringen levels on admission compared to controls. In addition, the plasma fibrinogen level was significantly higher in those with severe acute respiratory syndrome than in those without it. Therefore, early elevated plasma fibrinogen level may be a risk marker for the severe acute respiratory syndrome development ${ }^{42}$. But there are also authors who found normal plasma fibrinogen levels ${ }^{41}$. Moreover, they consider that high level of plasma D-dimer that coexists with normal fibrinogen levels is a characteristic finding in these patients and correlates with the disease severity and thrombotic risk ${ }^{41}$. A level of D-dimer more than 6 times higher than the upper limit of normal values can be found in patients with the highest thrombotic risk ${ }^{41}$. High levels of D-dimers are associated with disease progression and may be the expression of fibrinolysis secondary to disseminated intravascular coagulation favored by infections and sepsis ${ }^{34}$. Therefore, elevated levels of D-dimers predict unfavorable outcome in these patients ${ }^{36}$. Their detection by active screening allows early intensive prophylaxis of venous thromboembolism ${ }^{41}$. In addition to increasing plasma levels of D-dimers, other markers of coagulation dysfunction in SARS-CoV2 are: decreased platelet count, increased INR, and the presence of fibrin degradation products ${ }^{33}$.

\section{Is there disseminated intravascular coagulation?}

There are authors who claim that severe forms of COVID-19 are frequently prone to develop disseminated intravascular coagulation, but it has a particularly prothrombotic character ${ }^{36}$. Instead, none of the 150 patients with COVID-19 analyzed in a multicenter study developed disseminated intravascular coagulation; coagulation factor VIII and von Willebrand factor antigen and activity had considerably increased levels, and $87.7 \%$ of those tested were positive for lupus anticoagulant ${ }^{43}$. Another analysis also provided evidence against the suspicion of disseminated intravascular coagulation in a group of 24 patients with severe forms of COVID-19 and found the presence of hypercoagulability, supported by thromboelastographic parameters $^{44}$.

\section{The role of complement activation}

The analysis of patients infected with SARS-CoV-2 established that complement activation is involved in the 
pathogenesis of the disease with different degrees of respiratory failure. This finding has practical implications: it offers a possible therapeutic target ${ }^{45}$. Complement activation is involved in microvascular injury syndrome and systemic thrombosis ${ }^{46}$. Discrete inflammatory lesions were found in the capillaries present in the alveolar septa, which also showed fibrin deposits in their lumen and neutrophilic infiltrates in the interalveolar septa. They coexisted with evidence of complement activation (C5b-9 and C4d deposits). Discrete inflammatory and thrombogenic microvascular lesions were also found in the skin of the same patients, who coexisted with C5b-9 and C4d deposits $^{47}$.

\section{Placental pathological aspects}

There is evidence that placentas can also be affected by SARS-CoV-2 infection: half of 20 placentas of women infected with the virus resulted in fetal vascular malperfusion or thrombotic manifestations in fetal vessels ${ }^{48}$, but without complement deposition ${ }^{46}$. Another analysis of 5 placentas of patients with COVID-19 found focal avascular villi and thrombi in larger fetal vessels responsible for fetal circulation disorder, but the births were with healthy newborns, at term. The absence of complement deposition suggests that in these cases virus-induced procoagulant activity was systemic ${ }^{49}$.

\section{The role of laboratory in highlighting hypercoagulability}

Coagulation times are rarely affected at the beginning of hospitalization of patients with COVID-19. Thus, aPTT was found prolonged in $6 \%$ of hospitalized patients in a study conducted in Wuhan, and PT - in 5\% of them ${ }^{34}$. However, aPTT was prolonged in $20 \%$ of patients with severe SARS-CoV-2 infection in a recent published study ${ }^{50}$. Of these, lupus anticoagulant was determined in 34 patients; most of the samples $(91 \%)$ were positive. Just the presence of a prolonged aPPT does not necessarily mean a risk of bleeding. If lupus anticoagulant is present, the patient is at risk for thrombosis. Only in vitro coagulation tests are affected by the presence of lupus anticoagulant ${ }^{50}$. The implication of lupus anticoagulant in increasing thrombotic risk is unquestionable, but no correlation has been found between this risk and the "strength" of lupus anticoagulants ${ }^{51}$. It is worth mentioning that The International Society on Thrombosis and Haemostasis recommends that lupus anticoagulant be detected using two different testing modalities. For example, Simmons DP et al. determined aPTT and dilute Russell's viper venom time, which provides additional diagnostic information $^{52}$. Lupus anticoagulant is the most commonly found marker of antiphospholipid syndrome in patients with severe forms of SARS-CoV-2 infection. But the presence of anti-cardiolipin and anti- $\beta 2$-glycoprotein I antibodies also constitute a significant thrombotic risk factor, even if the patients infected with this virus do not have a history of anti-phospholipid syndrome ${ }^{53}$.

Elevated levels of D-dimer correlate with increased biomarkers of inflammation, such as interleukin-6, C-reactive protein, and erythrocyte sedimentation rates ${ }^{34}$ and with unfavorable prognosis. Thrombocytopenia was present in $12 \%$ of the patients in the Wuhan study, but some had other co-infections or even septic shock ${ }^{34}$.

Evaluation of coagulation using rotational thromboelastometry is useful for deepening the understanding of the disorders that occur in SARS-CoV-2 infection. Forty patients with severe pneumonia caused by SARS-CoV-2 and hospitalized in an intensive care unit were investigated in a retrospective analysis. PT was slightly below normal on admission and was significantly prolonged on day ten. In contrast, fibrinogen and aPTT values were higher on admission than on the tenth day. Hypercoagulability was supported by thrombelastography: patients had an acceleration of the propagation phase of blood clot formation and the clot strength was higher ${ }^{38}$. High fibrinogen and D-dimer plasma values, along with a short clot formation time and a high maximum clot firmness were also found in another thrombelastometric analysis made on patients with acute respiratory failure produced by COVID-19 $9^{54}$. Hypercoagulability manifested itself in the first five days, and it decreased ten days later, without reaching normal values. Signs of secondary hyperfibrinolysis or coagulopathy due to septic status have not been reported ${ }^{38}$. It can be concluded that patients with severe forms of COVID-19 have mainly severe hypercoagulability and not a consumptive coagulopathy, given these findings ${ }^{54}$.

Inflammatory response to infection with SARS-CoV-2 is more pronounced in some patients, which explains more severe changes in coagulation tests. High levels of D-dimer may be present, but especially as the disease progresses $^{34}$. High fibrinogen levels were found in all patients on admission ${ }^{55}$.

\section{The role of dynamic hematological and coagulation monitoring}

Useful tests to monitor the coagulation of patients infected with SARS-CoV-2 are: D-dimer, aPTT, PT, fibrinogen, and platelet count. The value of D-dimer may increase, PT, and aPTT may elongate, and the level of fibrinogen and platelet count may decrease during hospitalization. Patients may progress to sepsis-induced coagulopathy or disseminated intravascular coagulopathy. Sometimes, prolonged hospitalization, various associated infections or mechanical ventilation may explain this evolution, which may be independent of COVID-19 effects ${ }^{34}$.

Blood count and coagulation tests differ from patient to patient, depending on the severity of COVID-19. So, neutrophil to lymphocyte ratio, plasma level of D-dimer, and plasma fibrinogen levels were significantly higher while the lymphocyte count was lower in severe forms compared to mild / moderate disease. Monitoring the dynamic changes that may occur regarding neutrophil to lymphocyte ratio and plasma D-dimers allows the differentiation of mild or moderate forms of the disease from severe ones ${ }^{56}$ and the transformation of an initially benign into a severe one. 


\section{THROMBOTIC AND HEMORRHAGIC RISK ASSESSMENT}

The assessment of the thrombotic and hemorrhagic risk of patients infected with SARS-CoV-2 should repeatedly be done throughout their monitoring period, and should take pre-existing and associated diseases, laboratory analysis, concomitant drugs used, and invasive procedures into account. This is the best strategy for adjusting prophylactic or curative anticoagulant treatment ${ }^{57}$.

All patients with severe clinical forms of COVID-19 have an increased thrombotic risk. Prophylactic anticoagulant treatment is indicated for them, unless there are contraindications, according to the consensus reached by Chinese researchers in April 2020 ( ref. $^{57}$ ). PADUA or IMPROVE risk models for thrombotic risk estimation are indicated for the evaluation of medical patients with mild or moderate forms of COVID-19. The thrombotic risk of the surgical patients with the same forms of the disease is indicated to be evaluated using CAPRINI risk model ${ }^{57}$.

\section{ANTITHROMBOTIC PROPHYLAXIS AND TREATMENT}

It is estimated that almost $20 \%$ of patients with COVID-19 have significant coagulation disorders, especially those with severe disease ${ }^{57}$. Thrombotic complications have been associated with an increased risk of all-cause death ${ }^{58}$. Venous thromboembolism may be the explanation even for some of the unexplained deaths of patients infected with SARS-CoV-2. The management of these cases is a challenge due to coagulation disorders and the complexity of anticoagulant therapy ${ }^{57}$.

\section{An argument for hydroxychloroquine therapy: its antithrombotic effect}

The arguments that clinicians relied on when they introduced hydroxychloroquine into the treatment of COVID-19 were the presence of antithrombotic and immunomodulatory effects, its lower toxicity compared to chloroquine and anti-viral properties observed in cell cultures and animal models. Some analyzes have shown a clinical improvement of viral disease in patients treated with hydroxychloroquine, but the results of extensive, randomized controlled studies were not published until mid-May 2020 (ref. $\left.{ }^{59}\right)$.

\section{Limits of prophylactic and curative doses of anticoagulants}

A large study was made in Milan, over almost two months, on 388 hospitalized patients with virologically confirmed COVID-19, in which all those hospitalized in intensive care units and $75 \%$ of the others received prophylactic anticoagulant treatment. Thromboembolic complications were presented in $7.7 \%$ of them (half on the first day of hospitalization). Venous thromboembolism was confirmed imagistically in $36 \%$ of suspects; ischemic stroke developed $2.5 \%$; acute coronary syndrome - $1.1 \%$; $2.2 \%$ of them had overt disseminated intravascular co- agulation $^{60}$. The rate of thrombotic complications was even higher in a multicenter prospective study that identified 64 episodes of clinically manifest thrombotic events (especially pulmonary embolisms) in a group of 150 patients diagnosed with COVID-19, despite anticoagulation. Circuit clotting occurred in $96 \%$ of those who required continuous renal replacement therapy ${ }^{43}$. Patients with severe forms of COVID-19 are prone to develop venous thromboembolic events even under prophylactic or curative anticoagulant treatment according to another analysis ( $69 \%$ of a group of 26 consecutive patients diagnosed with complete duplex ultrasound in the study by Llitjos JF et al.). Venous thromboembolic events were significantly more frequent in those who received prophylactic doses. But those who were treated with therapeutic doses also had frequent venous thromboembolic events $(56 \%$ in the same study) (ref. ${ }^{61}$ ). However, higher anticoagulation targets are indicated for COVID-19 patients with severe disease $^{43}$.

\section{Heparinotherapy is able to reduce mortality}

An analysis found that heparinotherapy (especially enoxaparin given at a dose of 40-60 mg / day for at least one week) was able to reduce the mortality of patients with severe form of COVID-19. Mortality increased in patients not treated with heparin in parallel with plasma levels of D-dimers ${ }^{62}$. Indeed, the prophylactic anticoagulant treatment, or, if the situation requires it, the curative one, is indicated throughout the hospitalization in all patients with COVID-19. It seems to decrease the morbidity of patients with coagulation dysfunction induced by sepsis or with high plasma D-dimers levels ${ }^{36}$. Daily enoxaparin doses should be higher for obese patients to achieve adequate plasma concentrations ${ }^{34}$.

\section{Low molecular weight heparin appears to be ineffective in severe forms of COVID-19}

There are authors who are not convinced of the usefulness of prophylactic therapy with low molecular weight heparin in patients with severe forms of COVID-19, who are frequently victims of severe hypercoagulability. They advocate the use of unfractionated heparin in these patients, in order to prevent thrombotic events and a possible evolution towards respiratory and multiorgan failure ${ }^{39}$.

\section{The need for high-prophylactic anticoagulant doses}

The recommendation for the administration of highprophylactic anticoagulant doses was made by the authors of an analysis of 184 patients with severe forms of COVID-19 who received prophylactic anticoagulant treatment at least in standard doses. However, $31 \%$ of them had thrombotic events. Thrombotic risk factors were age and the presence of coagulopathy (PT over $3 \mathrm{~s}$ or aPTT over $5 \mathrm{~s})\left(\right.$ ref. $\left.^{63}\right)$. Currently, there are no studies supporting the usefulness of full-dose anticoagulation for the prophylaxis of microvascular thrombosis during severe infection ${ }^{34}$. Lupus anticoagulant and anti-phospholipid antibodies may be transiently positive in acute infections, with no clinical signs, and do not require anticoagulant treatment. But, their presence in COVID-19 patients is 
an indication for full intensity prophylactic anticoagulant treatment ${ }^{53,64}$.

\section{The high plasma levels of D-dimers indicate the need for higher doses of anticoagulant prophylaxis}

An analysis on deep venous thrombosis development was performed in patients with COVID-19 pneumonia and plasma D-dimer level over $1000 \mathrm{ng} / \mathrm{mL}$ who received standard thromboprophylactic treatment. Asymptomatic deep vein thrombosis was diagnosed in the absence of complete venous compression with the transducer on Doppler ultrasound examination. This asymptomatic complication was associated with a plasma D-dimer level above $1570 \mathrm{ng} / \mathrm{mL}$, but its incidence was the same as deep vein thrombosis observed in other series. Patients with deep vein thrombosis had higher median plasma D-dimer level (4527 ng/mL) compared to those without this complication ${ }^{65}$. Higher doses of anticoagulant used for prophylactic purposes would be discussed in patients with high plasma levels of D-dimers.

The benefits of previous chronic anticoagulant treatment

Patients infected with SARS-CoV-2 who had a critical illness for which they needed hospitalization in intensive care units had a high incidence of thrombotic events (especially pulmonary embolism), although they received prophylactic anticoagulant treatment. The risk was lower in those undergoing chronic anticoagulant treatment on admission $^{58}$

\section{Observations on the risks of oral anticoagulant treatment}

Plasma levels of direct oral anticoagulants increased dramatically in a group of patients infected with SARSCoV-2 during the antiviral treatment, according to the analysis made at Cremona Hospital. The authors recommended replacing the oral anticoagulant therapy with the parenteral therapy until the patients are discharged ${ }^{66}$. Another analysis found that the use of vitamin $\mathrm{K}$ antagonists in patients infected with SARS-CoV-2 during hospitalization is followed by large variations in INR values, and the administration of direct oral anticoagulants frequently leads to under / over coagulability. Therefore, parenterally administered heparin is indicated for the treatment of coagulation disorders in these hospitalized patients $^{67}$.

\section{The management of vascular prosthetic grafts in patients with SARS-CoV-2 infection}

Vascular prosthetic grafts have a risk of thrombosis when patients suffer from COVID-19, even under prophylactic anticoagulant treatment. A complete thrombosis of the aortic graft in such a patient has recently been reported. A more aggressive prophylactic anticoagulant treatment is indicated in this category of patients ${ }^{68}$. But thrombosis can also occur in the coronary stents in these patients. Antifibrinolytic therapy followed by rescue coronary angioplasty failed to protect a patient with a previous ST-segment elevation myocardial infarction and COVID-19 (without clinical manifestations) against 2 successive episodes of stent thrombosis. The authors of the article suspect a possible platelet hyperaggregability induced by SARS-CoV-2 virus infection, for which they recommend rapid revascularization associated with the use of new generation P2Y12 inhibitors and GPIIb/IIIa inhibitors ${ }^{69}$.

\section{Other useful prophylaxis and treatment measures}

Preventing dehydration and proper rehydration in patients who have experienced diarrhea or vomiting and active mobilization to the extent possible are means of decreasing thrombotic risk ${ }^{57}$.

Resolving inflammation using soluble epoxide hydrolase inhibitors and / or resolvins is an important way to decrease the thrombotic process and promote clot removal $^{70}$

Patients on anticoagulant therapy for other indications at the time of SARS-CoV-2 infection should continue their anticoagulant treatment at full dose or a dose equivalent to their current dose ${ }^{34}$.

Unfractionated heparin is indicated instead of low molecular weight heparin in patients with a creatinine clearance value below $30 \mathrm{~mL} / \mathrm{min}$ (ref. ${ }^{57}$ ).

Elevated baseline levels of D-dimers in COVID-19 patients cannot be an argument for pulmonary thromboembolism, and chest examination by computed tomography is not easy to perform in mechanically ventilated patients. If respiratory dysfunction suddenly worsens and a rightheart strain is found on echocardiography in a patient with ultrasonographically deep vein thrombosis, the suspicion of pulmonary thromboembolism is high and requires appropriate anticoagulant treatment ${ }^{34}$.

Nonheparin anticoagulant therapies are indicated in cases of proven or suspected heparin-induced thrombocytopenia ${ }^{57}$.

Nebulizer plasminogen activators may be a target to reduce fibrin deposition and improve oxygenation in the lungs of patients with severe COVID-19 pneumonia ${ }^{15}$.

Intermittent pneumatic compression is indicated in patients with severe or critical forms of COVID-19 who have active bleeding or an increased risk of bleeding, in whom anticoagulant therapy should be delayed ${ }^{57}$.

Thrombolytic therapy is discussed in patients with clinical signs of massive or high-risk pulmonary thromboembolism (systemic arterial hypotension or hemodynamic impairment), supported by bedside echocardiographic examination data $^{57}$.

\section{Hypercoagulability may persist after healing the SARS- CoV-2 infection}

Some of the patients who were immunized after healing the SARS-CoV-2 infection had a hypercoagulable state and were prone to develop thrombotic events. Plasma rich in neutralizing antibodies from fully recovered COVID-19 voluntary donors obtained by plasmapheresis or affinity column- derived antibodies is able to decrease hyperviscozity and reduce the thrombotic risk of donors. Three doses of such antiviral antibodies will neutralize the viral antigens of the critically ill COVID-19 recipients, which 
may reduce their predisposition to thrombotic complications $^{71}$.

\section{CONCLUSIONS}

Hypercoagulability is an essential component of the pathogenesis of SARS-CoV-2 infection, overwhelmingly influencing the evolution of severe forms and can even lead to the death of patients.

Careful detection and treatment of pre-existing and associated diseases, which increase the individual risk of the patient, and the prompt recognition and treatment of infections, which may be followed by cardiovascular or thrombotic complications, are other key objectives of SARS-CoV-2 patient management.

The decision regarding the prophylactic anticoagulant treatment should be personalized and made after a clinical analysis based on individual patient assessment that includes baseline venous throboembolism risk factors, bleeding risk factors, and associated conditions. The prophylactic anticoagulant treatment, or, if the situation requires it, the curative one, is indicated throughout the hospitalization in all patients with COVID-19. It seems to decrease the morbidity of patients with coagulation dysfunction induced by sepsis or with high plasma D-dimers levels ${ }^{36}$

Currently, there are no studies supporting the usefulness of full-dose anticoagulation for the prophylaxis of microvascular thrombosis during severe infection ${ }^{34}$. But advanced age, the presence of coagulopathy, or high levels of D-dimers on admission or their progressive increase during hospitalization are associated with increased thrombotic risk and could be an argument for high-prophylactic anticoagulant doses.

Careful monitoring (clinical, biological and imaging) of the patient's progress throughout the hospitalization period and periodic re-evaluation of thrombotic risk are necessary means to reduce thrombotic events and deaths. Prolonged hospitalization, especially in intensive care units, is associated with increased levels of D-dimers that can lead to multiorgan failure and disseminated intravascular coagulation.

In the absence of associated factors, the occurrence of bleeding in patients infected with SARS-CoV-2 should require measures for the diagnosis and treatment of sepsis-induced coagulopathy or disseminated intravascular coagulopathy ${ }^{34}$.

It is necessary to develop guidelines for the prophylaxis and treatment of thrombotic events, based on clinical experience, but taking into account especially multicenter clinical trials and not only observational studies.

\section{Search strategy and selection criteria}

Strategy research aimed at analyzing the coagulation disorders that occur during SARS-CoV-2 infection, their prophylaxis and treatment. Scientific articles published in PubMed and Web of Science databases. prior to 18.05.2020 were searched, using the terms "coagulation disorder", "COVID-19”, "SARS-CoV-2", "thrombosis”.

\section{ABBREVIATIONS}

activated partial thromboplastin time, aPTT; coronavirus disease-2019, COVID-19; prothrombin time, PT; severe acute respiratory syndrome, SARS; severe acute respiratory syndrome coronavirus 2, SARS-CoV-2.

Author contributions: Both authors contributed equally to the selection of articles, the elaboration of the manuscript, its correction and the final approval.

Conflict of interest statement: The authors declare that there are no conflicts of interest regarding the publication of this article.

\section{REFERENCES}

1. Montalvan V, Lee J, Bueso T, De Toledo J, Rivas K. Neurological manifestations of COVID-19 and other coronavirus infections: A systematic review. Clin Neurol Neurosurg 2020;194:105921.

2. Álvarez-Román MT, García-Barcenilla S, Cebanu T, GonzálezZorrilla E, Butta NV, I Bello-Fernández, Martín-Salces M, PollmarRivas I, Jiménez-Yuste V. Clinical trials and Haemophilia during the COVID-19' pandemic: Madrid's Experience. Haemophilia 2020 May 16. [Epub ahead of print] doi: 10.1111/hae.14055

3. Khan IH, Savarimuthu S, Leung MST, Harky A. The need to manage the risk of thromboembolism in COVID-19 patients. J Vasc Surg 2020 May 14. [Epub ahead of print] doi: 10.1016/j.jvs.2020.05.015

4. Xu X, Chang XN, Pan HX, Su H, Huang B, Yang M, Luo DJ, Weng MX, Ma L, Nie X. Pathological changes of the spleen in ten patients with new coronavirus infection by minimally invasive autopsies. Zhonghua Bing Li Xue Za Zhi 2020;49(0):E014.

5. Sardu C, Gambardella J, Morelli MB, Wang X, Marfella R, Santulli G. Hypertension, Thrombosis, Kidney Failure, and Diabetes: Is COVID-19 an Endothelial Disease? A Comprehensive Evaluation of Clinical and Basic Evidence. J Clin Med 2020;9(5):1417.

6. Hess DC, Eldahshan W, Rutkowski E. COVID-19-Related Stroke. Transl Stroke Res 2020;11(3):322-5.

7. Kaur P, Qaqa F, Ramahi A, Shamoon Y, Singhal M, Shamoon F, Maroules M, Singh B. Acute upper limb ischemia in a patient with COVID-19. Hematol Oncol Stem Cell Ther 2020 May 13. [Epub ahead of print] doi: 10.1016/j.hemonc.2020.05.001

8. Ciceri F, Beretta L, Scandroglio AM, Colombo S, Landoni G, Ruggeri A, Peccatori J, D'Angelo A, De Cobelli F, Rovere-Querini P, Tresoldi M, Dagna L, Zangrillo A. Microvascular COVID-19 lung vessels obstructive thromboinflammatory syndrome (MicroCLOTS): an atypical acute respiratory distress syndrome working hypothesis. Crit Care Resusc 2020;22(2):95-7.

9. Liu PP, Blet A, Smyth D, Li H. The Science Underlying COVID-19: Implications for the Cardiovascular System. Circulation 2020;142(1):68-78.

10. Zhang T, Sun LX, Feng RE. Comparison of clinical and pathological features between severe acute respiratory syndrome and coronavirus disease 2019. Zhonghua Jie He He Hu Xi Za Zhi 2020;43(6):496502.

11. Amiral J, Vissac AM, Seghatchian J. Covid-19, induced activation of hemostasis, and immune reactions: Can an auto-immune reaction contribute to the delayed severe complications observed in some patients? Transfus Apher Sci 2020;59(3):102804.

12. Bouaziz JD, Duong $T$, Jachiet $M$, Velter $C$, Lestang $P$, Cassius $C$, Arsouze A, Domergue Than Trong E, Bagot M, Begon E, Sulimovic L, Rybojad M. Vascular skin symptoms in COVID-19: a french observational study. J Eur Acad Dermatol Venereol 2020 Apr 27. [Epub ahead of print] doi: 10.1111/jdv.16544

13. Zuo Y, Yalavarthi S, Shi H, Gockman K, Zuo M, Madison JA, Blair CN, Weber A, Barnes BJ, Egeblad M, Woods RJ, Kanthi Y, Knight JS. Neutrophil extracellular traps in COVID-19. JCI Insight 2020;5(11):e138999.

14. Bikdeli B, Madhavan MV, Jimenez D, Chuich T, Dreyfus I, Driggin E, Nigoghossian C, Ageno W, Madjid M, Guo Y, Tang LV, Hu Y, Giri J, 
Cushman M, Quéré I, Dimakakos EP, Gibson CM, Lippi G, Favaloro EJ, Fareed J, Caprini JA, Tafur AJ, Burton JR, Francese DP, Wang EY, Falanga A, McLintock C, Hunt BJ, Spyropoulos AC, Barnes GD, Eikelboom JW, Weinberg I, Schulman S, Carrier M, Piazza G, Beckman JA, Steg PG, Stone GW, Rosenkranz S, Goldhaber SZ, Parikh SA, Monreal M, Krumholz HM, Konstantinides SV, Weitz JI, Lip GYH. COVID-19 and Thrombotic or Thromboembolic Disease: Implications for Prevention, Antithrombotic Therapy, and Follow-up. J Am Coll Cardiol 2020;75(23):2950-73.

15. Whyte CS, Morrow GB, Mitchell JL, Chowdary P, Mutch NJ. Fibrinolytic abnormalities in acute respiratory distress syndrome (ARDS) and versatility of thrombolytic drugs to treat COVID-19. J Thromb Haemost 2020;18(7):1548-55.

16. Harenberg J, Favaloro E. COVID-19: progression of disease and intravascular coagulation - present status and future perspectives. Clin Chem Lab Med 2020;58(7):1029-36.

17. Zhang W, Zhao Y, Zhang F, Wang Q, Li T, Liu Z, Wang J, Qin Y, Zhang $X$, Yan $X$, Zeng $X$, Zhang $S$. The use of anti-inflammatory drugs in the treatment of people with severe coronavirus disease 2019 (COVID-19): The Perspectives of clinical immunologists from China. Clin Immunol 2020;214:108393.

18. A Beccara L, Pacioni C, Ponton S, Francavilla S, Cuzzoli A. Arterial Mesenteric Thrombosis as a Complication of SARS-CoV-2 Infection. Eur J Case Rep Intern Med 2020;7(5):001690.

19. de Barry O, Mekki A, Diffre C, Seror M, Hajjam ME, Carlier RY. Arterial and venous abdominal thrombosis in a 79-year-old woman with COVID-19 pneumonia. Radiol Case Rep 2020;15(7):1054-7.

20. Hughes C, Nichols T, Pike M, Subbe C, Elghenzai S. Cerebral Venous Sinus Thrombosis as a Presentation of COVID-19. Eur J Case Rep Intern Med. 2020;7(5):001691.

21. Fischer MJ, Rauch J, Levine JS. The antiphospholipid syndrome. Semin Nephrol 2007;27(1):35-46.

22. Saba L, Sverzellati N. Is COVID Evolution Due to Occurrence of Pulmonary Vascular Thrombosis? J Thorac Imaging 2020 Apr 28. [Epub ahead of print] doi: 10.1097/RTI.00000000000000530

23. Harzallah I, Debliquis A, Drénou B. Frequency of lupus anticoagulant in Covid-19 patients. J Thromb Haemost 2020 May 29. [Epub ahead of print] doi: 10.1111/jth.14937

24. Tang N. Response to "Lupus anticoagulant is frequent in patients with Covid-19". J Thromb Haemost. 2020 May 7. [Epub ahead of print] doi: $10.1111 /$ jth. 14890

25. Wichmann D, Sperhake JP, Lütgehetmann $M$, Steurer $S$, Edler C, Heinemann A, Heinrich F, Mushumba $H$, Kniep I, Schröder AS, Burdelski C, de Heer G, Nierhaus A, Frings D, Pfefferle S, Becker H, Bredereke-Wiedling $\mathrm{H}$, de Weerth $A$, Paschen HR, SheikhzadehEggers S, Stang A, Schmiedel S, Bokemeyer C, Addo MM Aepfelbacher M, Püschel K, Kluge S. Autopsy Findings and Venous Thromboembolism in Patients With COVID-19: A Prospective Cohort Study. Ann Intern Med 2020 May 6. [Epub ahead of print] doi: 10.7326/M20-2003

26. Debuc B, Smadja DM. Is COVID-19 a New Hematologic Disease? [published online ahead of print, 2020 May 12, 1-5. Stem Cell Rev Rep 2020 May 12. [Epub ahead of print] doi: 10.1007/s12015-02009987-4.

27. Bhayana R, Som A, Li MD, Carey DE, Anderson MA, Blake MA, Catalano O, Gee MS, Hahn PF, Harisinghani M, Kilcoyne A, Lee SI, Mojtahed A, Pandharipande PV, Pierce TT, Rosman DA, Saini S, Samir AE, Simeone JF, Gervais DA, Velmahos G, Misdraji J, Kambadakone A. Abdominal Imaging Findings in COVID-19: Preliminary Observations. Radiology 2020 May 11. [Epub ahead of print] doi: $10.1148 /$ radiol.2020201908

28. Fox S, Dugar S. Point-of-care ultrasound and COVID-19. Cleve Clin J Med 2020 May 14. [Epub ahead of print] doi:10.3949/ccjm.87a. ccc019

29. Terpos E, Ntanasis-Stathopoulos I, Elalamy I, Kastritis E, Sergentanis TN, Politou M, Psaltopoulou T, Gerotziafas G, Dimopoulos MA. Hematological findings and complications of COVID-19. Am Hematol 2020;95(7):834-47.

30. Zhang L, Zhu F, Xie L, Wang C, Wang J, Chen R, Jia P, Guan HQ, Peng L, Chen Y, Peng P, Zhang P, Chu Q, Shen Q, Wang Y, Xu SY, Zhao JP, Zhou M. Clinical characteristics of COVID-19-infected cancer patients: a retrospective case study in three hospitals within Wuhan, China. Ann Oncol 2020;31(7):894-901.

31. Chen $X$, Yang $Y$, Huang $M$, Liu L, Zhang $X$, Xu J, Geng S, Han B, Xiao $J$, Wan Y. Differences between COVID-19 and suspected then con- firmed SARS-CoV-2-negative pneumonia: A retrospective study from a single center. J Med Virol 2020 Apr 1. [Epub ahead of print] doi: 10.1002/jmv. 25810

32. Henry BM, Vikse J, Benoit S, Favaloro EJ, Lippi G. Hyperinflammation and derangement of renin-angiotensin-aldosterone system in COVID-19: A novel hypothesis for clinically suspected hypercoagulopathy and microvascular immunothrombosis. Clin Chim Acta 2020;507:167-73.

33. Menezes-Rodrigues FS, Padrão Tavares JG, Pires de Oliveira M, Guzella de Carvalho R, Ruggero Errante P, Omar Taha M, Fagundes DJ, Caricati-Neto A. Anticoagulant and antiarrhythmic effects of heparin in the treatment of COVID-19 patients. J Thromb Haemost 2020 May 14. [Epub ahead of print] doi:10.1111/jth.14902

34. Connors JM, Levy JH. COVID-19 and its implications for thrombosis and anticoagulation. Blood 2020;135(23):2033-40.

35. Tal S, Spectre G, Kornowski R, Perl L. Venous Thromboembolism Complicated with COVID-19: What Do We Know So Far? Acta Haematol 2020 May 12. [Epub ahead of print] doi: $10.1159 / 000508233$

36. Kollias A, Kyriakoulis KG, Dimakakos E, Poulakou G, Stergiou GS, Syrigos K. Thromboembolic risk and anticoagulant therapy in COVID-19 patients: emerging evidence and call for action. $\mathrm{Br} J$ Haematol 2020;189(5):846-7.

37. Middeldorp S, Coppens M, van Haaps TF, Foppen M, Vlaar AP, Müller MCA, Bouman CCS, Beenen LFM, Kootte RS, Heijmans J, Smits LP, Bonta PI, van Es N. Incidence of venous thromboembolism in hospitalized patients with COVID-19. J Thromb Haemost 2020 May 5. [Epub ahead of print] doi: 10.1111/jth.14888

38. Pavoni V, Gianesello L, Pazzi M, Stera C, Meconi T, Frigieri FC. Evaluation of coagulation function by rotation thromboelastometry in critically ill patients with severe COVID-19 pneumonia. J Thromb Thrombolysis 2020;50(2):281-6.

39. Barrett CD, Moore HB, Yaffe MB, Moore EE. ISTH interim guidance on recognition and management of coagulopathy in COVID-19: A Comment. J Thromb Haemost. 2020 Apr 17. [Epub ahead of print] doi: $10.1111 /$ jth. 14860

40. Baldacini M, Pop R, Sattler L, Mauvieux L, Bilger K, Gantzer J, Schneider F, Beaujeux R, Simand C, Herbrecht R. Concomitant hemorrhagic syndrome and recurrent extensive arterial thrombosis in a patient with COVID-19 and acute promyelocytic leukemia. $\mathrm{Br} J$ Haematol 2020;189(6):1054-6.

41. Mucha SR, Dugar S, McCrae K, Joseph DE, Bartholomew J, Sacha G, Militello M. Coagulopathy in COVID-19. Cleve Clin J Med 2020 Jun 10. [Epub ahead of print] doi: 10.3949/ccjm.87a.ccc024

42. Di Micco P, Russo V, Carannante N, Imparato M, Rodolfi S, Cardillo G, Lodigiani C. Clotting Factors in COVID-19: Epidemiological Association and Prognostic Values in Different Clinical Presentations in an Italian Cohort. J Clin Med 2020;9(5):1371.

43. Helms J, Tacquard C, Severac F, Leonard-Lorant I, Ohana M, Delabranche X, Merdji H, Clere-Jehl R, Schenck M, Fagot Gandet F, Fafi-Kremer S, Castelain V, Schneider F, Grunebaum L, AnglésCano E, Sattler L, Mertes PM, Meziani F; CRICS TRIGGERSEP Group (Clinical Research in Intensive Care and Sepsis Trial Group for Global Evaluation and Research in Sepsis). High risk of thrombosis in patients with severe SARS-CoV-2 infection: a multicenter prospective cohort study. Intensive Care Med 2020;46(6):1089-98.

44. Panigada M, Bottino N, Tagliabue P, Grasselli G, Novembrino C, Chantarangkul V, Pesenti A, Peyvandi F, Tripodi A. Hypercoagulability of COVID-19 patients in Intensive Care Unit. A Report of Thromboelastography Findings and other Parameters of Hemostasis. JThromb Haemost 2020;18(7):1738-42.

45. Cugno M, Meroni PL, Gualtierotti R, Griffini S, Grovetti E, Torri A, Panigada M, Aliberti S, Blasi F, Tedesco F, Peyvandi F. Complement activation in patients with covid-19: A novel therapeutic target. J Allergy Clin Immunol 2020;146(1):215-7. doi: 10.1016/j. jaci.2020.05.006

46. Mulvey JJ, Magro CM, Ma LX, Nuovo GJ, Baergen RN. Analysis of complement deposition and viral RNA in placentas of COVID-19 patients. Ann Diagn Pathol 2020 Apr 25. [Epub ahead of print] doi: 10.1016/j.anndiagpath.2020.151530

47. Magro C, Mulvey JJ, Berlin D, Nuovo G, Salvatore S, Harp J, BaxterStoltzfus A, Laurence J. Complement associated microvascular injury and thrombosis in the pathogenesis of severe COVID-19 infection: a report of five cases. Transl Res 2020;220:1-13. 
48. Baergen RN, Heller DS. Placental Pathology in Covid-19 Positive Mothers: Preliminary Findings. Pediatr Dev Pathol 2020;23(3):177-80.

49. Mulvey JJ, Magro CM, Ma LX, Nuovo GJ, Baergen RN. A mechanistic analysis placental intravascular thrombus formation in COVID-19 patients. Ann Diagn Pathol 2020 Apr 25. [Epub ahead of print] doi: 10.1016/j.anndiagpath.2020.151529

50. Bowles L, Platton S, Yartey N, Dave M, Lee K, Hart DP, MacDonald V, Green L, Sivapalaratnam S, Pasi KJ, MacCallum P. Lupus Anticoagulant and Abnormal Coagulation Tests in Patients with Covid-19. N Engl J Med 2020;383(3):288-90.

51. Moffat K, Raby A, Crowther M. Lupus anticoagulant testing. Methods Mol Biol 2013;992:97-108.

52. Simmons DP, Herskovits AZ, Battinelli EM, Schur PH, Lemire SJ, Dorfman DM. Lupus anticoagulant testing using two parallel methods detects additional cases and predicts persistent positivity. Clin Chem Lab Med 2018;56(8):1289-96.

53. Aubignat M, Godefroy O. COVID-19 and ischemic stroke: Should we systematically look for lupus anticoagulant and antiphospholipid antibodies? Rev Neurol (Paris) 2020;176(6):505-6.

54. Spiezia L, Boscolo A, Poletto F, Cerruti L, Tiberio I, Campello E, Navalesi P, Simioni P. COVID-19-Related Severe Hypercoagulability in Patients Admitted to Intensive Care Unit for Acute Respiratory Failure. Thromb Haemost 2020;120(6):998-1000.

55. Tang N, Li D, Wang X, Sun Z. Abnormal coagulation parameters are associated with poor prognosis in patients with novel coronavirus pneumonia. J Thromb Haemost 2020;18(4):844-7.

56. Fu J, Kong J, Wang W, Wu M, Yao L, Wang Z, Jin J, Wu D, Yu X. The clinical implication of dynamic neutrophil to lymphocyte ratio and D-dimer in COVID-19: A retrospective study in Suzhou China. Thromb Res 2020;192:3-8.

57. Zhai Z, Li C, Chen Y, Gerotziafas G, Zhang Z, Wan J, Liu P, Elalamy I, Wang C; Prevention Treatment of VTE Associated with COVID-19 Infection Consensus Statement Group. Prevention and Treatment of Venous Thromboembolism Associated with Coronavirus Disease 2019 Infection: A Consensus Statement before Guidelines. Thromb Haemost 2020;120(6):937-48.

58. Klok FA, Kruip MJHA, van der Meer NJM, Arbous MS, Gommers D, Kant KM, Kaptein FHJ, van Paassen J, Stals MAM, Huisman MV, Endeman $\mathrm{H}$. Confirmation of the high cumulative incidence of thrombotic complications in critically ill ICU patients with COVID-19: An updated analysis. Thromb Res 2020;191:148-50.

59. Quiros Roldan E, Biasiotto G, Magro P, Zanella I. The possible mechanisms of action of 4-aminoquinolines (chloroquine/hydroxychloroquine) against Sars-Cov-2 infection (COVID-19): A role for iron homeostasis? Pharmacol Res 2020;158:104904.

60. Lodigiani C, lapichino G, Carenzo L, Cecconi M, Ferrazzi P, Sebastian T, Kucher N, Studt JD, Sacco C, Alexia B, Sandri MT, Barco S; Humanitas COVID-19 Task Force. Venous and arterial thromboembolic compli- cations in COVID-19 patients admitted to an academic hospital in Milan, Italy. Thromb Res 2020;191:9-14.

61. Llitjos JF, Leclerc M, Chochois C, Monsallier JM, Ramakers M, Auvray $\mathrm{M}$, Merouani K. High incidence of venous thromboembolic events in anticoagulated severe COVID-19 patients. J Thromb Haemost 2020;18(7):1743-6.

62. Porfidia A, Pola R. Venous thromboembolism in COVID-19 patients. J Thromb Haemost 2020;18(6):1516-7.

63. Klok FA, Kruip MJHA, van der Meer NJM, Arbous MS, Gommers DAMPJ, Kant KM, Kaptein FHJ, van Paassen J, Stals MAM, Huisman $\mathrm{MV}$, Endeman $\mathrm{H}$. Incidence of thrombotic complications in critically ill ICU patients with COVID-19. Thromb Res 2020;191:145-7.

64. Radic M., Pattanaik D. Cellular and molecular mechanisms of antiphospholipid syndrome. Front Immunol 2018;9:969.

65. Demelo-Rodríguez $P$, Cervilla-Muñoz E, Ordieres-Ortega L, ParraVirto A, Toledano-Macías M, Toledo-Samaniego N, García-García A, García-Fernández-Bravo I, Ji Z, de-Miguel-Diez J, Álvarez-SalaWalther LA, Del-Toro-Cervera J, Galeano-Valle F. Incidence of asymptomatic deep vein thrombosis in patients with COVID-19 pneumonia and elevated D-dimer levels. Thromb Res 2020;192:23-6.

66. Testa S, Prandoni P, Paoletti O, Morandini R, Tala M, Dellanoce $C$ Giorgi-Pierfranceschi M, Betti M, Battista Danzi G, Pan A, Palareti G. Direct oral anticoagulant plasma levels' striking increase in severe COVID-19 respiratory syndrome patients treated with antiviral agents: The Cremona experience. J Thromb Haemost 2020;18(6):1320-3.

67. Testa S, Paoletti O, Giorgi-Pierfranceschi M, Pan A. Switch from oral anticoagulants to parenteral heparin in SARS-CoV-2 hospitalized patients. Intern Emerg Med 2020 Apr 15. [Epub ahead of print] doi: 10.1007/s11739-020-02331-1

68. Giacomelli E, Dorigo W, Fargion A, Calugi G, Cianchi G, Pratesi C. Acute Thrombosis of an Aortic Prosthetic Graft in a Patient with Severe COVID-19-Related Pneumonia. Ann Vasc Surg 2020;66:8-10.

69. Lacour T, Semaan C, Genet T, Ivanes F. Insights for increased risk of failed fibrinolytic therapy and stent thrombosis associated with COVID-19 in ST-segment elevation myocardial infarction patients. Catheter Cardiovasc Interv 2020 Apr 30. [Epub ahead of print] doi: $10.1002 /$ ccd. 28948

70. Panigrahy D, Gilligan MM, Huang S, Gartung A, Cortés-Puch I, Sime PJ, Phipps RP, Serhan CN, Hammock BD. Inflammation resolution: a dual-pronged approach to averting cytokine storms in COVID-19? Cancer Metastasis Rev 2020;39(2):337-40.

71. Seghatchian J, Lanza F. Convalescent plasma, an apheresis research project targeting and motivating the fully recovered COVID 19 patients: A rousing message of clinical benefit to both donors and recipients alike. Transfus Apher Sci 2020;59(3):102794. [Epub ahead of print] doi: 10.1016/j.transci.2020.102792 